\title{
Curing Kinetics of Allylester Resins from Differential Scanning Calorimetry
}

\author{
Jyongsik JANG and Jieun YI \\ Department of Chemical Technology, \\ College of Engineering, Seoul National University, \\ San 56-1, Shinlimdong, Kwanakgu, \\ Seoul 151-742, Korea
}

(Received October 11, 1995)

\begin{abstract}
Allylester prepolymers were synthesized by transesterification and curing kinetics of allylester resins was studied by differential scanning calorimetry. The activation energy and the frequency factor of the allylester prepolymers were estimated by using Ozawa and Kissinger methods. The order of the activation energy and the frequency factor was diallyl terephthalate $+1,3$-butylene glycol $<$ diallyl isophthalate $+1,3$-butylene glycol $<$ diallyl isophthalate + diethylene glycol in both methods. The values determined from Ozawa method are higher than those from Kissinger method. The exothermic peak temperature of allylester resin was shifted to lower temperature region with increasing concentration of curing agent. In this experiment, both the activation energy and the frequency factor decreased as the concentration of curing agent increased. When the mixed curing agent was used, the exothermic peak temperature appeared between those corresponding to each curing agents.
\end{abstract}

KEY WORDS Allylester / Transesterification / Differential Scanning Calorimetry / Curing Kinetics / Activation Energy / Frequency Factor / Dicumyl Peroxide /

Allylester resin has many advantages, which are a variety of the mechanical property, long shelf-life, and thermal stability, because it is cured after preparation of prepolymer by transesterification differently from allyl system polymer what it used to be. ${ }^{1-4}$ Besides, it has weathering stability, chemical resistance, heat resistance, corrosional resistance, distinguished optical properties, and excellent electric resistance at elevated temperature and high humidity. Therefore, allylester resin can be widely used in many applications such as optical material, building material, artificial marble, wire board, and so forth. ${ }^{5,6}$

Especially, as the prepolymerization is not accomplished by radical reaction but by transesterification, it is easy to change the content and type of polyol and diallyl ester. There is also facility of modification of the molecular structure and performance of polymer at will.
It takes too long time to cure the system completely and that is pointed out as weakness of allylester resin. It is, however, expected there can be possibility of some applications to the new processing which is unable as before. Their utilities lie in the extremely wide variety of chemical reactions that can be used for the curing and the many different properties that results. On the other hand, the applications of allylester resins are restricted due to the limited information concerning the cure kinetics of allylester resins.

Therefore, it is important to verify the cure kinetics for the various applications of this allylester.

There are several techniques to monitor the cure process such as infrared absorption spectroscopy, DC conductivity, and differential scanning calorimetry (DSC). ${ }^{7-13}$ In this study, the DSC technique was employed to investi- 
gate the curing reaction of allylester prepolymers with dicumyl peroxide and tert-butyl peroxybenzoate as curing agent. For the cure study on the allylester, three kinds of allylester prepolymer have been synthesized through transesterification using diallyl terephthalate + 1,3-butylene glycol, diallyl isophthalate $+1,3$ butylene glycol, and diallyl isophthalate $+\mathrm{di}-$ ethylene glycol. Subsequently, DSC experiments have been carried out to estimate the activation energy $(E)$ and the frequency factor $(A)$ of curing of allylester resin. ${ }^{14-17}$ The experimental results were analyzed by using Ozawa and Kissinger methods. These methods, which the system is cured on various heating rates, are simple and valuable for the study of cure kinetics.

The ultimate goals of this study are to synthesize some allylester prepolymers by transesterification as well as to determine the activation energy and the frequency factor of curing of allylester resins. In addition, it has been carried out to elucidate the effect of the concentration of curing agent on the curing kinetics.

\section{EXPERIMENTAL}

\section{Materials}

Diallyl monomers used in this study were diallyl terephthalate (DAT) and diallyl isophthalate (DAIP) provided by DAISO in Japan. 1,3-Butylene glycol (1,3-BG) and diethylene glycol (DEG) were used as diols for transesterification. Monobutyltin oxide (MBO) was used as catalyst and dicumyl peroxide (DCP) and tert-butyl peroxybenzoate (TBPB) were used as curing agents in this study.

Table I shows the chemical structures of the materials employed in this experiment.

\section{Synthesis}

Three kinds of prepolymer were prepared from DAT + 1,3-BG, DAIP + 1,3-BG, and DAIP+DEG with stirring at more than 100 rpm under the nitrogen atmosphere. $\mathrm{MBO}$ as
Table I. Chemical structures of the materials used in allylester cure kinetics

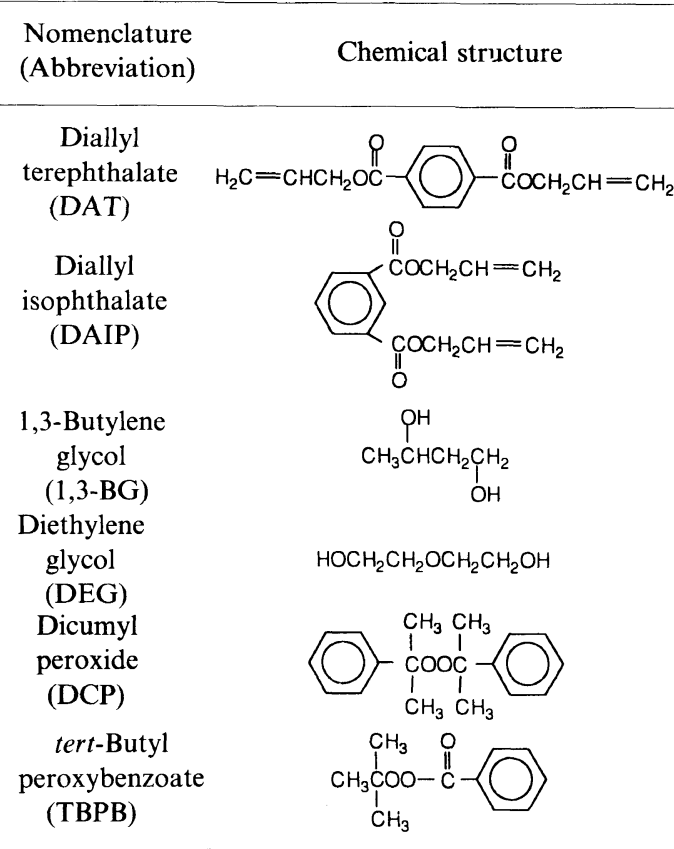

catalyst was added by $1000 \mathrm{ppm}$ on the basis of diallyl monomers. The reaction temperature for prepolymer was $190^{\circ} \mathrm{C}$, and the initial molar ratio of diallyl monomer/diol was 1.6. Allyl alcohol as by-product was removed by Dean stark trap and the removal of diols was prevented by the different boiling points between allyl alcohol and diols. The transesterification was carried out for about $5 \mathrm{~h}$ and unreacted diol and remained allyl alcohol were removed by the vaccum distillation at 50 Torr.

\section{Infrared Spectroscopy}

The structure of prepolymers prepared was verified by infrared spectroscopy using a PerkinElmer 1725-X FT-IR spectrometer. Transmission measurement was performed in the following procedures; casting the prepolymers from acetone solution on $\mathrm{KBr}$ window and scanning 32 times for each sample with a resolution of $2 \mathrm{~cm}^{-1}$.

Infrared spectra were also obtained for the reactants, 1,3-BG, DEG, DAT, and DAIP, and 
by-product, allyl acohol by preceding method without solvent.

\section{Nuclear Magnetic Resonance Spectroscopy}

The verification of the structure of prepolymers was also carried out by nuclear magnetic resonance spectroscopy using a VXR-200 ${ }^{1} \mathrm{H}$ NMR spectrometer. Deuterium substituted chloroform $\left(\mathrm{CDCl}_{3}\right)$ and tetramethylsilane (TMS) were used as a solvent and a standard material, respectively.

\section{Curing and Differential Scanning Calorimetry}

Curing experiments were achieved by Setaram DSC 92 with the three kinds of prepolymers. Heating rate $(\phi)$ was changed respectively 5 , 10,15 , and $20^{\circ} \mathrm{Cmin}^{-1}$ and the temperature range was $80-300^{\circ} \mathrm{C}$. The instrument was calibrated for the scanning temperature and the enthalpy with high purity titanium. DCP was used by 3 phr as curing agent.

For DAT + 1,3-BG prepolymer, curing experiments were carried out by changing the DCP concentration by $1,2,3,4$, and 5 phr at a heating rate $10^{\circ} \mathrm{C} \mathrm{min}-1$.

In order to determine the activation energy and the frequency factor of allylester resins, curing experiments were performed as a function of DCP concentration; 2, 3, and $4 \mathrm{phr}$ with $\mathrm{DAT}+1,3-\mathrm{BG}$ prepolymer. Heating rates were $5,10,15$, and $20^{\circ} \mathrm{C} \mathrm{min}^{-1}$.

To study the effect of different curing agents, experiments were also carried out at a fixed total curing agent concenration of $3 \mathrm{phr}$ and the mass ratio for DCP/TBPB was varied from 1.0 to 0 at an interval of 0.25 .

Each sample of $15-20 \mathrm{mg}$ in crimped aluminum cell was cured in the DSC under nitrogen atmosphere. An empty cell was used as the reference. $^{18}$

\section{THEORETICAL}

The relationships between the heating rates and the exothermic peak temperatures were independently suggested by Ozawa and Kissin- ger.

Ozawa derived the following relationship about the heating rate, the exothermic peak temperature, and the activation energy, simply but accurately.

Generally, the cure rate of thermoset resin is described by eq 1

$$
\frac{\mathrm{d} \alpha}{\mathrm{d} t}=k \cdot f(\alpha)
$$

where $\alpha$ is the degree of cure, $k$ is the reaction rate constant. It is assumed that the rate constant obeys the Arrhenius dependence on the cure temperature,

$$
k=A \exp (-E / R T)
$$

where $A$ is the frequency factor. The time derivative of degree of cure can be expressed as eq 3 .

$$
\frac{\mathrm{d} \alpha}{\mathrm{d} t}=A \cdot f(\alpha) \cdot \exp (-E / R T)
$$

$f(\alpha)$ equals $(1-\alpha)^{n}$ in general case and $\alpha^{m}(1-$ $\alpha)^{n}$ in the case of auto-catalytic reaction.

At a given heating rate $(\phi=\mathrm{d} T / \mathrm{d} t)$, rearrange the above eq 3 ,

$$
\frac{\mathrm{d} \alpha}{f(\alpha)}=\frac{A}{\phi} \exp (-E / R T) \mathrm{d} T
$$

integrate eq 4 from 0 to the degree of cure at the peak temperature $\left(\alpha_{p}\right)$,

$$
\begin{aligned}
\int_{0}^{\alpha_{\mathrm{p}}} \frac{\mathrm{d} \alpha}{f(\alpha)} & =\frac{A}{\phi} \int_{T_{0}}^{T_{\mathrm{p}}} \exp (-E / R T) \mathrm{d} T \\
& \cong \frac{A}{\phi} \int_{0}^{T_{\mathrm{p}}} \exp (-E / R T) \mathrm{d} T \\
& =\left(\frac{A E}{\phi R}\right) \cdot P(E / R T)
\end{aligned}
$$

where $T_{0}$ is the initial temperature and $T_{\mathrm{p}}$ is the peak temperature.

Doyle suggested the following approximation on the value of $P(E / R T) .{ }^{19}$

$$
\log P(E / R T) \cong-2.315-0.4567(E / R T)
$$


The assumption of the constancy of $\alpha_{p}$ has been ascertained by many investigators. Therefore, the following equation is derived from eq 5 and 6.

$$
E=\frac{-R}{0.4567} \cdot \frac{\Delta \log \phi}{\Delta\left(1 / T_{\mathrm{p}}\right)}=\frac{-R}{1.052} \cdot \frac{\Delta \ln \phi}{\Delta\left(1 / T_{\mathrm{p}}\right)}
$$

The activation energy $(E)$ can be obtained from the slope of $1 / T_{\mathrm{p}}$ versus $\ln \phi$. This method has advantages of brevity, relative accuracy, and insensitivity of secondary factors such as solvent effect, accuracy of base line.

The activation energy was obtained by Ozawa method which was based on the assumption that the degree of cure at the peak temperature is constant and independent of heating rates. Duswaalt reported that the activation energy could be obtained with a precision of $3 \%$ and estimated accuracy of $10 \%$ from the eq $7 .^{20}$

Kissinger differentiated the eq 4 and obtained

$$
\frac{\mathrm{d}\left[\ln \left(\phi / T_{\mathrm{p}}^{2}\right)\right]}{\mathrm{d}\left(1 / T_{\mathrm{p}}\right)}=-\frac{E}{R}
$$

If the reaction obeys the $n$-th order reaction, $f(\alpha)$ can be expressed by $(1-\alpha)^{n}$ then,

$$
\frac{\mathrm{d} \alpha}{\mathrm{d} t}=A \cdot(1-\alpha)^{n} \cdot \exp (-E / R T)
$$

From the above assumption, the second order derivative of degree of cure with respect to time should be zero at peak temperature. As a second approximation, Kissinger asserted that the value of $n\left(1-\alpha_{p}\right)^{n-1}$ was about unity irrespective of heating rates. Then,

$$
A=\frac{\phi E \cdot \exp \left(E / R T_{\mathrm{p}}\right)}{R T_{\mathrm{p}}^{2} \cdot\left[n\left(1-\alpha_{\mathrm{p}}\right)^{n-1}\right]} \cong \frac{\phi E \cdot \exp \left(E / R T_{\mathrm{p}}\right)}{R T_{\mathrm{p}}^{2}}
$$

this was confirmed by several workers. ${ }^{21}$

In order to determine the frequency factor, Kissinger method was employed, in which DSC peak is assumed to correspond to the maximum reaction rate was employed. ${ }^{21,22}$

Therefore, the activation energy can be ob- tained from the slope in the plot of $\ln \left(\phi / T_{\mathrm{p}}^{2}\right)$ versus $1 / T_{p}$ and the frequency factor can be expressed in terms of $E$ and $T_{\mathrm{p}}$ from eq 10.

These methods are simple and convenient in comparison with Cut-and-Weigh method and Spectroscopic method. ${ }^{23}$ Besides, Rogers and Smith reported that the above methods were independent of sample size. ${ }^{24}$

\section{RESULTS AND DISCUSSION}

Three kinds of liquid prepolymer (DAT + 1,3-BG, DAIP + 1,3-BG, and DAIP + DEG) were synthesized by transesterification. The conversions of products were $89-93 \%$. Allyl alcohol as by-product was confirmed by comparing FT-IR spectrum with literature. ${ }^{25}$ It means that only allyl alcohol was removed through the Dean stark trap because the boiling point difference is about $130^{\circ} \mathrm{C}^{26}$

Figure 1 shows the FT-IR transmission spectra of the synthetic prepolymers. In 2850 $3000 \mathrm{~cm}^{-1}$ region (a), al and a2 indicate $\mathrm{C}-\mathrm{H}$ characteristic peak of 1,3-BG and a3 demonstrates $\mathrm{C}-\mathrm{H}$ characteristic peak of DEG. In $1100-1300 \mathrm{~cm}^{-1}$ region (b), b1 represents the characteristic peak of 1,4-substituted aromatic ring and b2 and b3 show the characteristic peak of 1,3-substituted aromatic ring.

Figure 2 shows the NMR spectra of prepolymers prepared. At $4.7 \mathrm{ppm}$, aliphatic $\mathrm{C}-\mathrm{H}$ characteristic peaks appear in three spectra. At $5.4 \mathrm{ppm},=\mathrm{C}-\mathrm{H}_{2}$ and at $6.0 \mathrm{ppm},=\mathrm{C}-\mathrm{H}-$ characteristic peaks were shown. In addition, aromatic $\mathrm{C}-\mathrm{H}$ characteristic peaks appear at $8.2 \mathrm{ppm}$. The characteristic peak at $3.8 \mathrm{ppm}$ which represents $\mathrm{O}-\mathrm{H}$ on 1,3-BG disappeared in spectra $\mathrm{A}$ and $\mathrm{B}$. The characteristic peak at $3.6 \mathrm{ppm}$ which shows $\mathrm{O}-\mathrm{H}$ on DEG also disappeared in spectrum C. ${ }^{27}$

Therefore, it was confirmed that the designed prepolymers have been synthesized.

Figures 3-5 show the DSC curves of synthetic prepolymers with the heating rates 5,10 , 15 , and $20^{\circ} \mathrm{C} \mathrm{min}^{-1}$. The faster the heating rate is, the higher exothermic peak temperature is. 


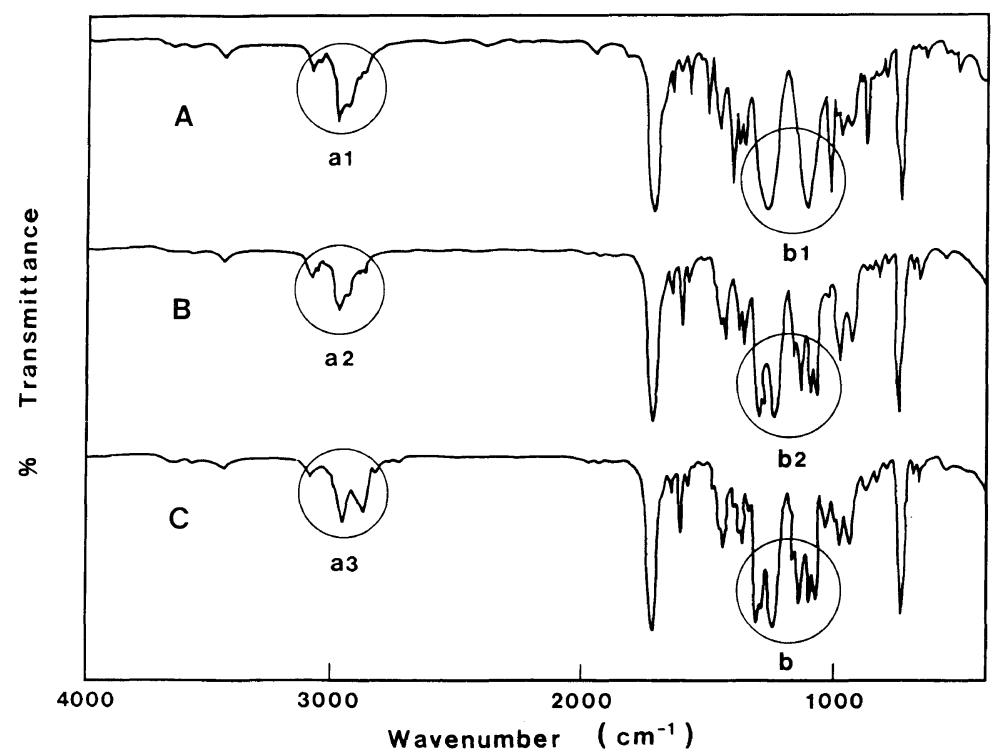

Figure 1. FT-IR transmission spectra for allylester prepolymers: DAT+1,3-BG (A), DAIP + 1,3-BG (B), and DAIP + DEG (C).

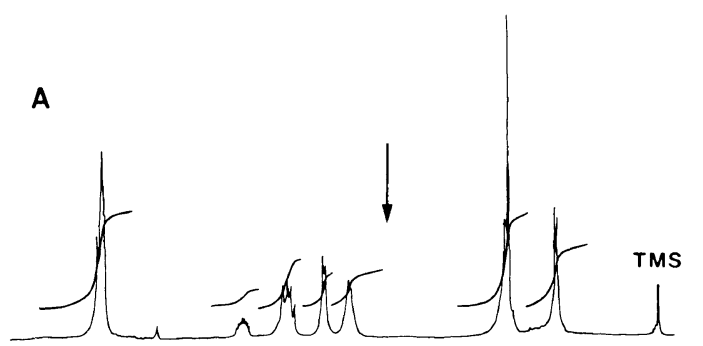

At the same heating rates, the exothermic peak temperatures shift to higher value in the order of DAT + 1,3-BG $<$ DAIP + 1,3-BG $<$ DAIP + DEG.

Figure 6 is the plot of $1 / T_{\mathrm{p}}$ versus $\ln \phi$ according to the eq 7 for each prepolymer. The slope is increased in the order of DAT $+1,3-$ BG $<$ DAIP + 1,3-BG $<$ DAIP + DEG. Each slope is DAT +1,3-BG: $-1.161 \times 10^{-4}$, DAIP + 1,3-BG: $-9.560 \times 10^{-5}$, and DAIP + DEG: $-8.645 \times 10^{-5}$. Figure 7 is also the plot of $\ln \left(\phi / T_{\mathrm{p}}^{2}\right)$ versus $1 / T_{\mathrm{p}}$ according to the eq 8 for each prepolymer. The slope is decreased in the order of DAT +1,3-BG $>$ DAIP + 1,3-BG $>$ DAIP + DEG. Each slope is DAT + 1,3-BG: $-7.638 \times 10^{3}, \mathrm{DAIP}+1,3-\mathrm{BG}:-9.221 \times 10^{3}$, and DAIP + DEG: $-1.031 \times 10^{3}$.

Figures 8-10 illustrate the plot for the eq 10 with the activation energies estimated from Ozawa and Kissinger methods.

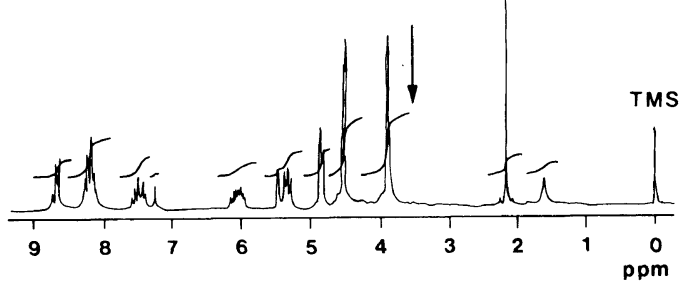

Table II shows each activation energy and

Figure 2. NMR spectra for allylester prepolymers: $\mathrm{DAT}+1,3-\mathrm{BG}$ (A), DAIP + 1,3-BG (B), and DAIP + DEG (C). 


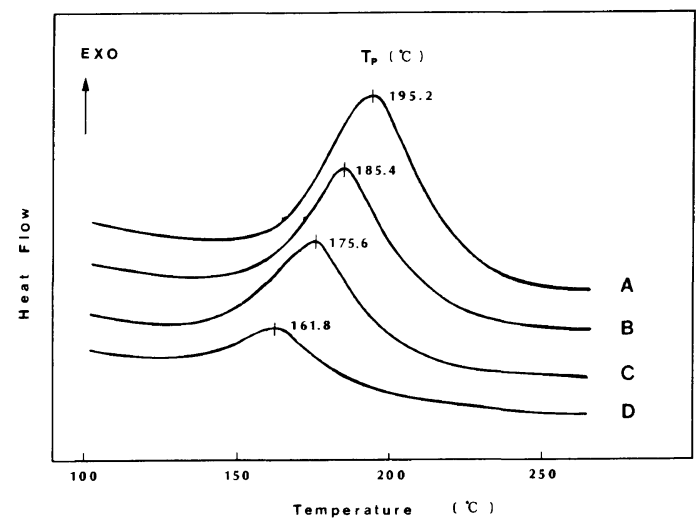

Figure 3. DSC curves of DAT +1,3-BG prepolymer at different heating rates: $20^{\circ} \mathrm{C} \mathrm{min}^{-1}$ (A), $15^{\circ} \mathrm{C} \mathrm{min}^{-1}$ (B), $10^{\circ} \mathrm{Cmin}^{-1}(\mathrm{C})$, and $5^{\circ} \mathrm{Cmin}^{-1}(\mathrm{D})$.

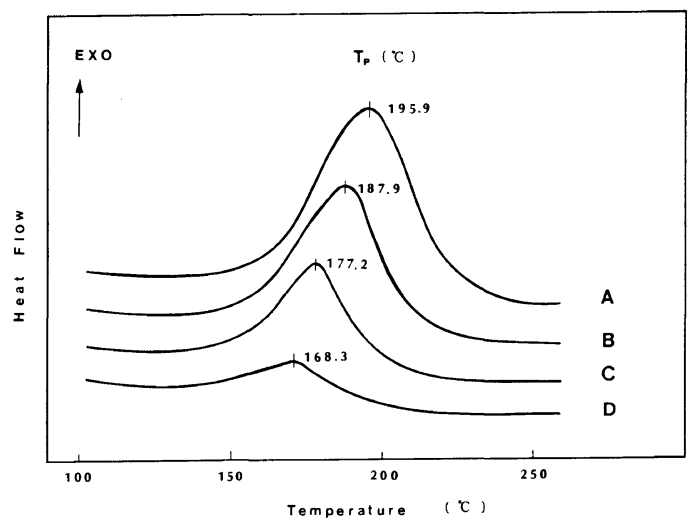

Figure 4. DSC curves of DAIP +1,3-BG prepolymer at different heating rates: $20^{\circ} \mathrm{C} \mathrm{min}^{-1}$ (A), $15^{\circ} \mathrm{C} \mathrm{min}^{-1}$ (B), $10 . \mathrm{Cmin}^{-1}(\mathrm{C})$, and $5^{\circ} \mathrm{Cmin}^{-1}(\mathrm{D})$.

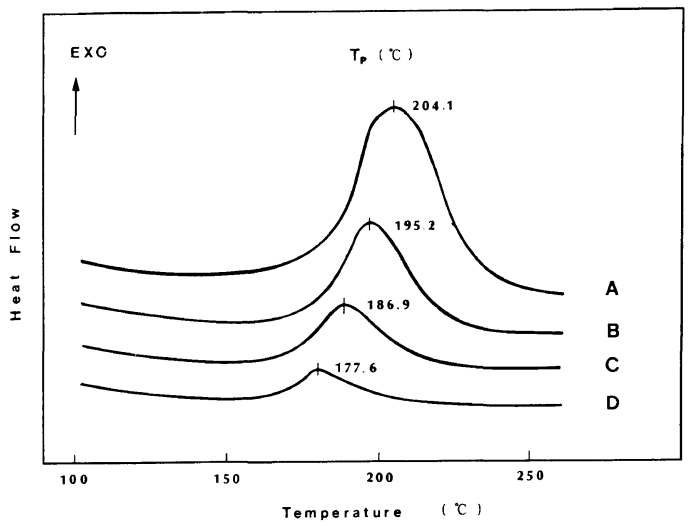

Figure 5. DSC curves of DAIP + DEG prepolymer at different heating rates: $20^{\circ} \mathrm{Cmin}^{-1}$ (A), $15^{\circ} \mathrm{Cmin}^{-1}$ (B), $10^{\circ} \mathrm{Cmin}^{-1}(\mathrm{C})$, and $5^{\circ} \mathrm{C} \min ^{-1}$ (D).

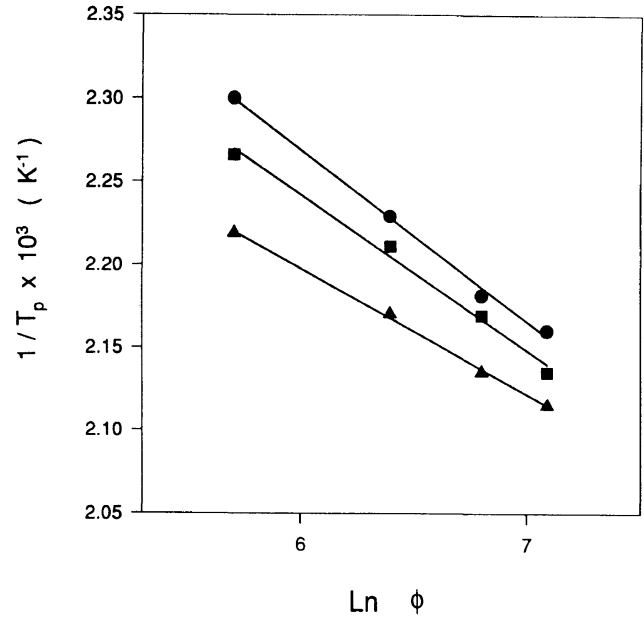

Figure 6. Plots for determination of the activation energy $(E)$ in the curing reaction by Ozawa method: DAT $+1,3-$ BG (O), DAIP + 1,3-BG (ם), and DAIP + DEG (A).

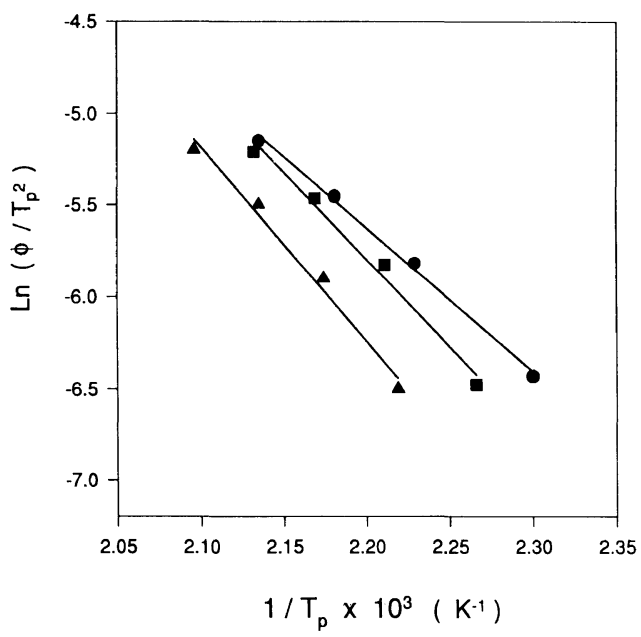

Figure 7. Plot for determination of the activation energy $(E)$ in the curing reaction by Kissinger method: DAT +

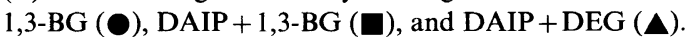

frequency factor for prepolymers estimated from Ozawa and Kissinger methods. We can see that the order of the activation energy and the frequency factor are DAT $+1,3-\mathrm{BG}<$ DAIP + 1,3-BG $<$ DAIP + DEG in both methods. But the values from Ozawa method are higher than those from Kissinger method.

It can be suggested that DAIP and DEG need more activation energy than DAT and 


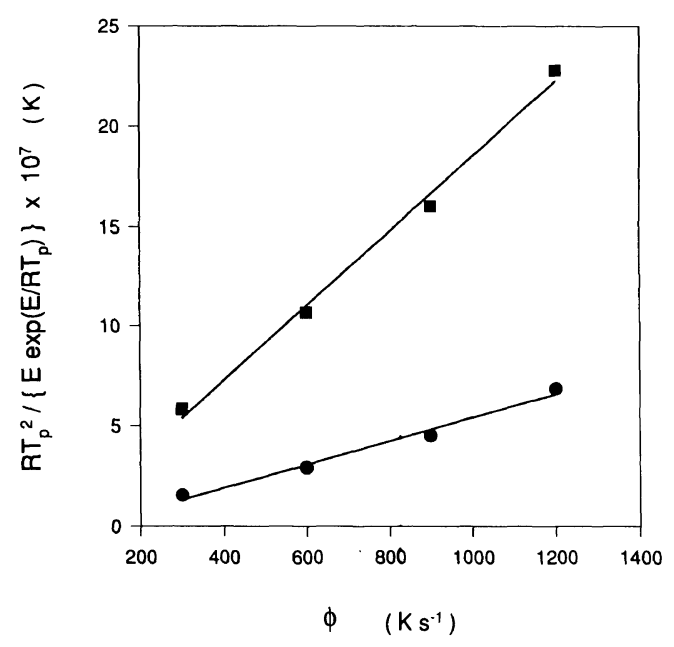

Figure 8. Plots for determination of the frequency factor $(A)$ in the curing reaction of DAT $+1,3-\mathrm{BG}$ prepolymer by Kissinger method from different $E$ : $E$ from Ozawa method (O) and $E$ from Kissinger method ( $\square$ ).

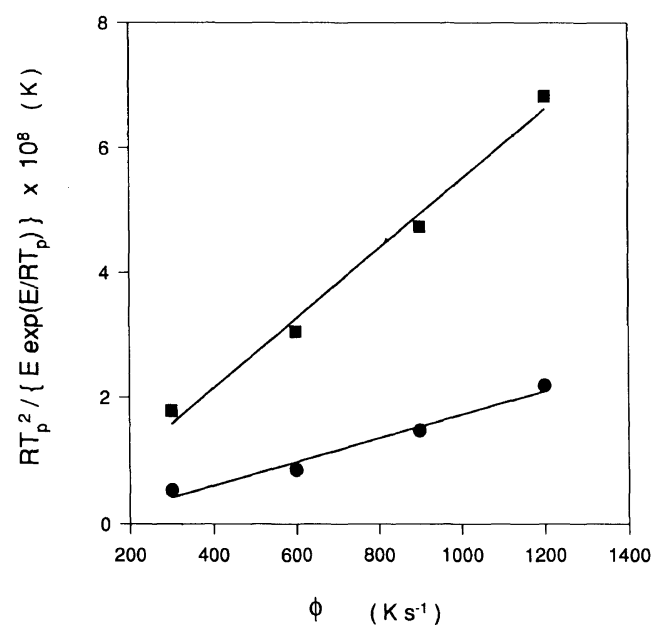

Figure 9. Plots for determination of the frequency factor $(A)$ in the curing reaction of DAIP $+1,3-\mathrm{BG}$ prepolymer by Kissinger method from different $E$ : $E$ from Ozawa method (O) and $E$ from Kissinger method ( $\square)$.
1,3-BG in curing reaction of allylester. It is supposed that DAIP and DEG are more favorable than DAT and 1,3-BG in the point of view of the effective collision. This can be primarily explained by the structures of these materials. This can be, however, closely examined by researching on the structure and the curing mechanism of prepolymers.

It is also inferred that the activation energy has more influence than the frequency factor from the fact that the order of the exothermic peak temperatures is DAT + 1,3-BG $<$ DAIP + 1,3-BG $<$ DAIP + DEG.

Table III shows the effect of the concentration of curing agent on the exothermic peak temperature determined for $\mathrm{DAT}+1,3-\mathrm{BG}$ prepolymer at a heating rate of $10^{\circ} \mathrm{Cmin}^{-1}$. The higher the concentration of curing agent,

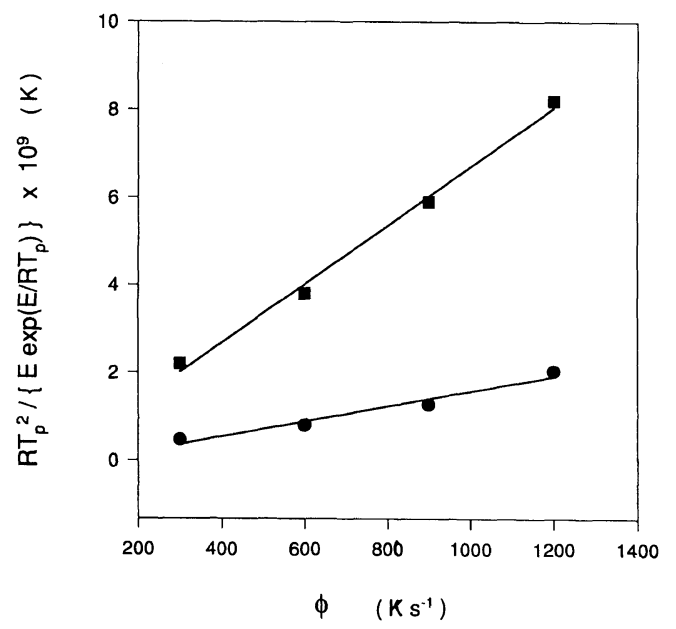

Figure 10. Plots for determination of the frequency factor $(A)$ in the curing reaction of DAIP + DEG prepolymer by Kissinger method from different $E$ : $E$ from Ozawa method (O) and $E$ from Kissinger method ( $\square$ ).

Table II. The activation energy and the frequency factor for allylester prepolymers from DSC experiment

\begin{tabular}{lccccc}
\hline \multirow{2}{*}{ Prepolymer } & \multicolumn{2}{c}{ Ozawa method } & & \multicolumn{2}{c}{ Kissinger method } \\
\cline { 2 - 3 } \cline { 5 - 6 } & $E / \mathrm{kJ} \mathrm{mol}^{-1}$ & $A / \mathrm{s}^{-1}$ & & $E / \mathrm{kJ} \mathrm{mol}^{-1}$ & $A / \mathrm{s}^{-1}$ \\
\hline DAT + 1,3-BG & 68.07 & $1.716 \times 10^{9}$ & & 63.51 & $5.101 \times 10^{8}$ \\
DAIP + 1,3-BG & 82.67 & $8.477 \times 10^{10}$ & & 76.67 & $1.740 \times 10^{10}$ \\
DAIP + DEG & 91.42 & $5.803 \times 10^{11}$ & & 85.73 & $1.331 \times 10^{11}$ \\
\hline
\end{tabular}


Table III. The exothermic peak temperature at different concentrations of curing agent

\begin{tabular}{|c|c|c|c|c|c|}
\hline $\begin{array}{l}\text { Curing agent } \\
\text { concentration }\end{array}$ & \multirow[t]{2}{*}{1} & \multirow[t]{2}{*}{2} & \multirow[t]{2}{*}{3} & \multirow[t]{2}{*}{4} & \multirow[t]{2}{*}{5} \\
\hline phr & & & & & \\
\hline Peak temp & \multirow{2}{*}{199.3} & \multirow{2}{*}{194.1} & \multirow{2}{*}{175.6} & \multirow{2}{*}{171.0} & \multirow{2}{*}{167.2} \\
\hline${ }^{\circ} \mathrm{C}$ & & & & & \\
\hline
\end{tabular}

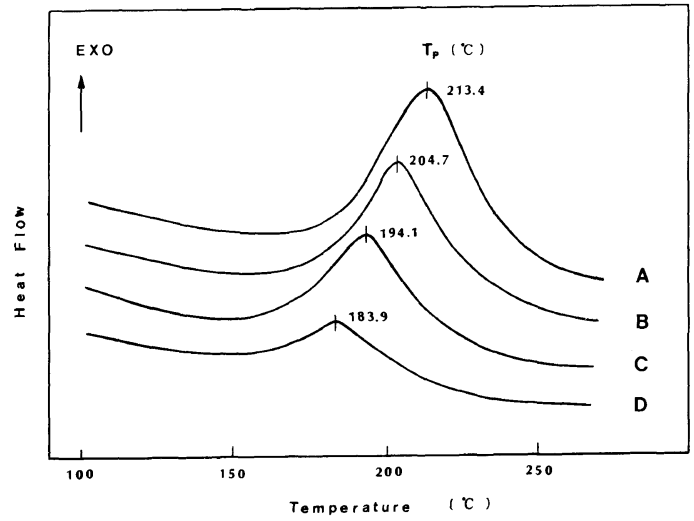

Figure 11. DSC curves of DAT +1,3-BG prepolymer with 2 phr of DCP at different heating rates: $20^{\circ} \mathrm{C} \mathrm{min}^{-1}$ (A), $15^{\circ} \mathrm{Cmin}^{-1}$ (B), $10^{\circ} \mathrm{Cmin}^{-1}$ (C), and $5^{\circ} \mathrm{Cmin}^{-1}$ (D).

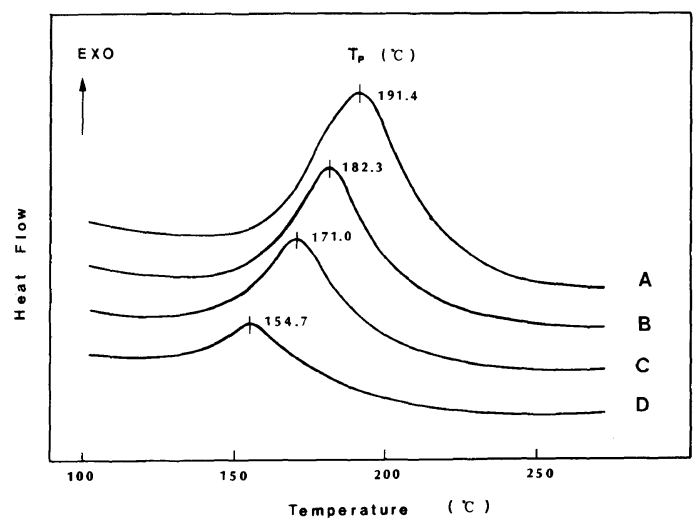

Figure 12. DSC curves of DAT +1,3-BG prepolymer with $4 \mathrm{phr}$ of DCP at different heating rates: $20^{\circ} \mathrm{Cmin}^{-1}$ (A), $15^{\circ} \mathrm{C} \mathrm{min}^{-1}$ (B), $10^{\circ} \mathrm{Cmin}^{-1}$ (C), and $5^{\circ} \mathrm{C} \mathrm{min}^{-1}$ (D).

the lower the exothermic peak temperature appears. This represents that with the high concentration of the curing agent, the maximum degree of cure was attained in the early stage.

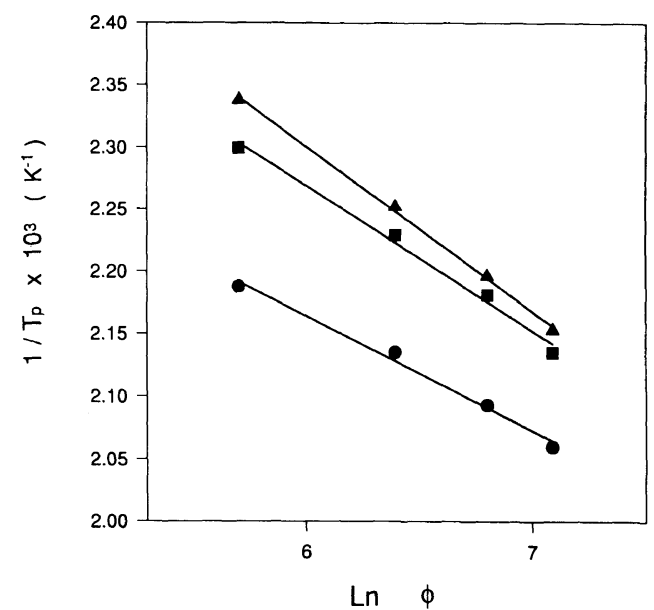

Figure 13. Plots for determination of the activation energy $(E)$ in the curing reaction with different curing agent concentration by Ozawa method: $2 \mathrm{phr}(\mathcal{O}), 3 \mathrm{phr}$ (ם), and 4 phr (A).

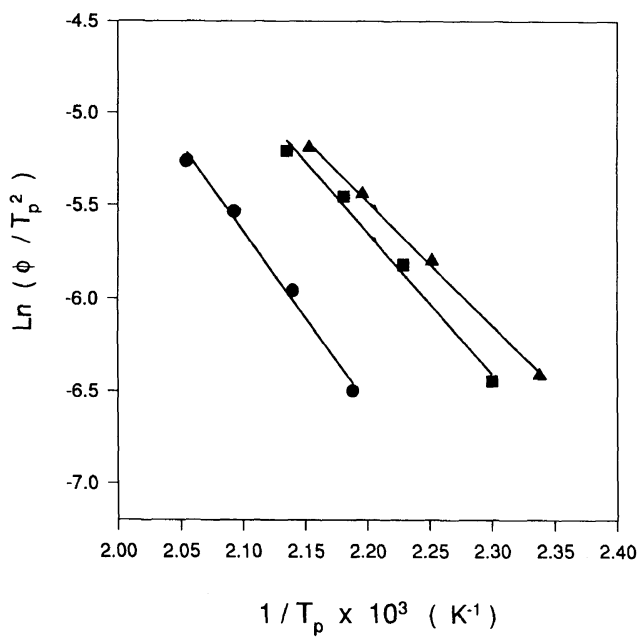

Figure 14. Plots for determination of the activation energy $(E)$ in the curing reaction with different curing agent concentration by Kissinger method: $2 \mathrm{phr}(\bigcirc), 3 \mathrm{phr}$ (西), and $4 \mathrm{phr}(\boldsymbol{\Delta})$.

It is presumed that the same tendency should appear for the other prepolymers such as DAIP + 1,3-BG and DAIP + DEG.

Figures 11 and 12 are DSC curves as changing heating rates by $5,10,15$, and $20^{\circ} \mathrm{C} \mathrm{min}^{-1}$ for DAT+1,3-BG prepolymer with the concentrations of curing agent of 2 and $4 \mathrm{phr}$, respectively. According to the previous meth- 


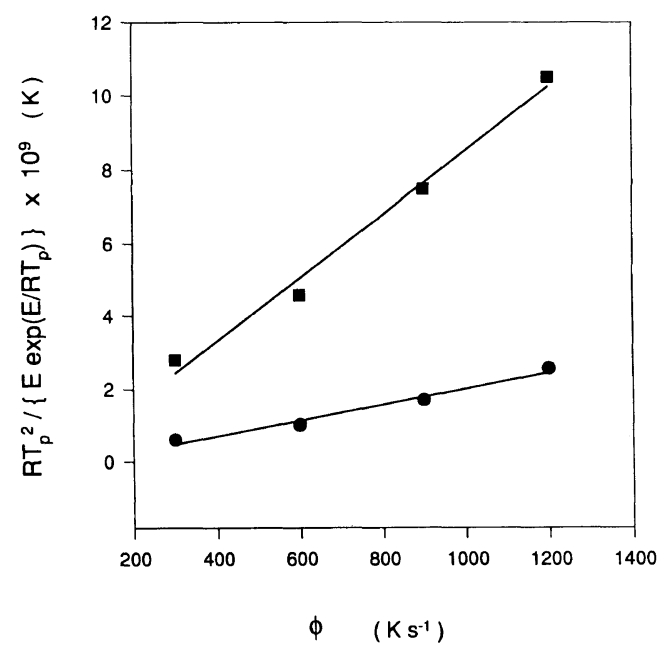

Figure 15. Plots for determination of the frequency factor $(A)$ in the curing reaction with the $2 \mathrm{phr}$ of DCP by Kissinger method from different $E$ : $E$ from Ozawa method (O) and $E$ from Kissinger method (

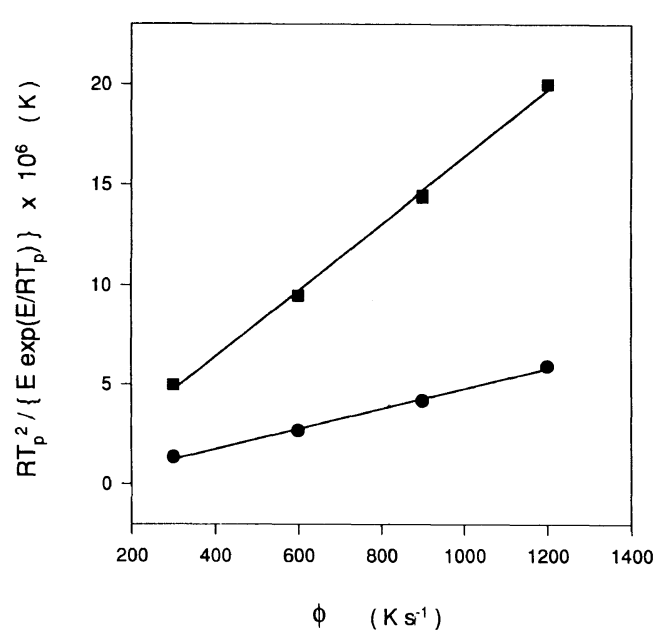

Figure 16. Plots for determination of the frequency factor $(A)$ in the curing reaction with the $4 \mathrm{phr}$ of DCP by Kissinger method from different $E$ : $E$ from Ozawa method (O) and $E$ from Kissinger method ( $\square$ ).

Table IV. The activation energy and the frequency factor for DAT $+1,3-\mathrm{BG}$ prepolymer at different concentrations of curing agent from DSC experiment

\begin{tabular}{|c|c|c|c|c|}
\hline \multirow{2}{*}{$\begin{array}{c}\begin{array}{c}\text { Curing agent } \\
\text { concentration }\end{array} \\
\mathrm{phr}\end{array}$} & \multicolumn{2}{|c|}{ Ozawa method } & \multicolumn{2}{|c|}{ Kissinger method } \\
\hline & $E / \mathrm{kJ} \mathrm{mol}^{-1}$ & $A / \mathrm{s}^{-1}$ & $E / \mathrm{kJ} \mathrm{mol}^{-1}$ & $A / \mathrm{s}^{-1}$ \\
\hline 2 & 83.48 & $4.551 \times 10^{10}$ & 77.87 & $1.091 \times 10^{10}$ \\
\hline 3 & 68.07 & $1.716 \times 10^{9}$ & 63.51 & $5.101 \times 10^{8}$ \\
\hline 4 & 59.64 & $1.969 \times 10^{8}$ & 55.23 & $6.001 \times 10^{7}$ \\
\hline
\end{tabular}

ods, Figures 13 and 14 were plotted at the different concentration of curing agent of 2,3 , and $4 \mathrm{phr}$, respectively by Ozawa method and Kissinger method. Figure 15 was plotted for the prepolymer which has DCP of $2 \mathrm{phr}$ in order to estimate the frequency factor from two different activation energies. On the other hand, Figure 16 was plotted for the prepolymer which has DCP of $4 \mathrm{phr}$ in order to estimate the frequency factor from two different activation energies. Each activation energy and frequency factor at each concentration of DCP is arranged at Table IV. As the concentration of the curing agent increases, both the activation energy and the frequency factor decrease. The values estimated from Ozawa method are also
Table V. The exothermic peak temperature at the use of mixed curing agents

\begin{tabular}{cccccc}
$\frac{\text { DCP:ТВPB }}{\text { wt }}$ & $4: 0$ & $3: 1$ & $2: 2$ & $1: 3$ & $0: 4$ \\
\hline $\begin{array}{c}\text { Peak temp } \\
{ }^{\circ} \mathrm{C}\end{array}$ & 175.6 & 177.7 & 186.6 & 188.9 & 214.5
\end{tabular}

higher than those from Kissinger method.

Table $\mathrm{V}$ shows the shift of the exothermic peak temperature as changing the ratio of mixed curing agent for DAT $+1,3-\mathrm{BG}$ prepolymer at the fixed total mass as $3 \mathrm{phr}$. The heating rate was fixed at $10^{\circ} \mathrm{Cmin}^{-1}$. 
The exothermic peak temperature appeared at $175.6^{\circ} \mathrm{C}$ when DCP was $100 \%$ and at $214.5^{\circ} \mathrm{C}$ when TBPB was $100 \%$. When the mixed curing agent was used, the exothermic peak temperature appeared between those corresponding to each component curing agents. From this result, we can infer that curing condition can be readily controlled by using the adequately mixed curing agents.

\section{CONCLUSION}

From the synthesis and curing kinetics of allylester prepolymers, it is concluded that,

1. Allylester prepolymers, DAT +1,3-BG, DAIP + 1,3-BG, and DAIP + DEG were effectively synthesized by transesterification.

2. The order of the activation energy and the frequency factor of the cured allylester resins is $\mathrm{DAT}+1,3-\mathrm{BG}<\mathrm{DAIP}+1,3-\mathrm{BG}<$ DAIP + DEG from the results of DSC experiment.

3. The values determined from Ozawa method are higher than those from Kissinger method.

4. High concentration of the curing agent promotes the maximum degree of cure in the early stage of reaction.

5. As the concentration of the curing agent increases, both the activation energy and the frequency factor of cured allylester resin decrease.

6. When the mixed curing agent was used, the exothermic peak temperatures appeared between those corresponding to each curing agents.

\section{REFERENCES}

1. A. Matsumoto, M. Miyagawa, M. Yamawaki, and M. Oiwa, J. Polym. Sci., Polym. Lett. Ed., 24, 7 (1986).

2. A. Matsumoto, Y. Ogasawara, S. Nishikawa, T. Aso, and M. Oiwa, J. Polym. Sci., A, Polym. Chem., 27, 839 (1989).
3. A. Matsumoto, M. Miyagawa, M. Yamawaki, and M. Oiwa, J. Appl. Polym. Sci., 29, 2241 (1984).

4. Y. Ohtsuka, H. Kawaguchi, and T. Hamasaki, J. Appl. Polym. Sci., 27, 1771 (1982).

5. C. E. Schildknecht, "Allyl Compounds and their Polymers," John Wiley \& Sons, New York, N.Y., 1973, Chapters 11 and 12.

6. T. Whelan, J. Goff, "Molding of Thermosetting Plastics," Van Nostrand Reinhold, New York, N.Y., 1990, pp 26-32.

7. R. N. Rogers and E. D. Morris, Jr., Anal. Chem., 38, 412 (1966).

8. K. E. J. Barrett, J. Appl. Polym. Sci., 10, 1617 (1967).

9. R. A. Fava, Polymer, 9, 137 (1968).

10. K. Horie, H. Hiura, M. Sawada, I. Mita, and $\mathrm{H}$ Kambe, J. Polym. Sci., 8, 1357 (1970).

11. L. W. Crane, P. J. Dynes, and D. H. Kaelble, J. Polym. Sci., Polym. Lett. Ed., 11, 533 (1973).

12. J. S. Shim, W. Lee, and J. Jang, Polym. J., 23, 903 (1991).

13. B. G. Min, Z. H. Stachurski, and J. H. Hodgkin, Polymer, 34, 21, 4488 (1993).

14. T. Ozawa, Bull. Chem. Sci., Jpn, 38, 11, 1881 (1965).

15. H. E. Kissinger, Anal. Chem., 29, 1702 (1957).

16. R. B. Prime, "Thermal Characterization of Polymeric Materials,” E. A. Turi, Ed., Academic Press, New York, 1983, Chapter 5.

17. H. E. Kissinger, J. Res. Natl. Standards, 57, 217 (1956).

18. ASTM E 698-79 (Reapproved 1984), 1992, pp 518-524.

19. C. D. Doyle, J. Appl. Polym. Sci., 6, 639 (1962).

20. A. A. Duswaalt, Thermochim. Acta, 8, 57 (1974).

21. R. B. Prime, Polym. Eng. Sci., 13, 5, 365 (1973).

22. T. Provder, R. M. Holsworth, T. H. Grentzer, and S. A. Kline, "Polymer Characterization," American Chemical Society, Washington, D.C., 1983, Chapter 13.

23. E. Immelman, N. Jahed, and R. D. Sandeson, Thermochim. Acta, 214, 277 (1993).

24. R. N. Rogers and L. C. Smith, Anal. Chem., 39, 1024 (1967).

25. D. R. Brezinski, Ed., "An Infrared Spectroscopy Atlas for the Coatings Industry," 4th ed., Federation of Societies for Coatings Technology, Pennsylvania, 1991, Chapter VIII.

26. R. J. Lewis, Ed., "Hazardous Chemicals Desk Reference," 2nd ed, Van Nostrand Reinhold, New York, N.Y., 1991.

27. C. J. Pouchert and J. Behnke, "The Aldrich Library of ${ }^{13} \mathrm{C}$ and ${ }^{1} \mathrm{H}$ FT NMR Spectra," Vol. 1 and 2, Aldrich Chemical Company Inc., Milwaukee, Wisc., 1993. 